\title{
O Paquistão e as estratégias ocidentais para a Ásia Meridional
}

\section{ABELARDO ARANTES JÚNIOR*}

Ao longo de 2002, a situação na Ásia Meridional mostrou-se tensa o bastante para justificar a preocupação das potências ocidentais. Paquistão e Índia, em uma de suas crises periódicas, concentraram cerca de um milhão de soldados em ambos os lados da Linha de Controle (LoC, na usual sigla inglesa) que divide a Cachemira e da fronteira comum. Embora as tensões diminuíssem, com a retirada das tropas indianas e paquistanesas para suas posições normais, permaneceu a animosidade entre os dois países. O governo dos Estados Unidos, potência externa mais atuante no quadro da Ásia Meridional, continua a manifestar sua preocupação com o estado político da região. Conforme declarado por Christina Rocca, Assistant Secretary of State para Assuntos do Sul da Ásia ao Comitê de Relações Exteriores do Senado norte-americano, "We helped to successfully walk India and Pakistan back from the brink of war last year". ${ }^{1}$ Mesmo que se julgue essa afirmação excessiva, é fato sabido que altos dirigentes dos Estados Unidos e de outras potências procuraram sucessivas vezes os governantes do Paquistão e da Índia, sugerindo moderação. Também é conhecida a séria preocupação revelada pelas autoridades paquistanesas, e por muitos observadores em Islamabade, a respeito dos riscos de degeneração das tensões com a Índia, a ponto de acabar em mais um conflito.

\section{Dados gerais da situação}

As tensões indo-paquistanesas têm raízes profundas e antigas. Em primeiro lugar, avulta a questão da Cachemira, vista em Islamabade como o core issue das relações bilaterais. O Paquistão acusa a Índia de se recusar a tratar, no âmbito bilateral, da questão que domina as demais, desde a independência de ambos, em 1947. Islamabade também acusa Nova Délhi de desrespeitar as resoluções da ONU sobre a matéria. A Índia, por sua vez, acusa o Paquistão de promover atentados na Cachemira indiana, por agente interposto, a saber, as organizações da jihad que a seu ver se baseiam em território paquistanês; para a Índia, as

\footnotetext{
Rev. Bras. Polít. Int. 46 (1): 182-207 [2003]

* Embaixador do Brasil no Paquistão. As opiniões constantes do presente artigo refletem apenas seus pontos de vista pessoais ou os das fontes que cita; não exprimem políticas oficiais do Brasil.
} 
ações da jihad não passam de cross-border terrorism, segundo a expressão costumeiramente empregada. A noção tem implicações importantes. Caso fosse aceita a tese indiana do "terrorismo transfronteiriço", o Paquistão ficaria contra a unanimidade internacional forjada após os atentados de 11 de setembro de 2001. O Paquistão, por sua vez, nega a existência de terrorismo transfronteiriço, através da LoC, e diz que essa acusação constitui tentativa da Índia de difamá-lo, de maneira a indispô-lo com a comunidade internacional e a encobrir as violações maciças de direitos humanos que a seu ver são cometidas pelas forças indianas na Cachemira.

As tensões entre o Paquistão e a Índia não representam apenas mais um quadro de confrontos, entre tantos outros. A Índia é a segunda nação mais populosa do mundo e conta com um dos maiores dispositivos militares do planeta. É clara sua intenção de prosseguir sua trajetória emergente, inclusive pela possível aquisição de lugar permanente no Conselho de Segurança da ONU. Com cerca de 140 milhões de habitantes, o Paquistão é o país muçulmano de maior população, após a Indonésia, e projeta constantemente seu papel no âmbito da Organização da Conferência Islâmica, que congrega cinqüenta e seis nações. Tanto o Paquistão quanto a Índia dispõem de armas nucleares e desenvolvem novos sistemas de mísseis.

As implicações internacionais também são consideráveis. O Paquistão é vizinho do Afeganistão; sua cooperação mostrou-se indispensável para o combate ao Talibã. Através do Afeganistão, a Ásia Central tem no Paquistão um escoadouro potencial para seus produtos, sobretudo para petróleo e gás natural. Ainda no que refere à região de contato entre a Ásia Meridional, a Ásia Central e o Oriente Médio, o Paquistão faz fronteira com o Irã. O litoral paquistanês, no Mar da Arábia, permite acesso rápido ao Golfo Pérsico e às rotas internacionais do petróleo.

A Índia, com sua população e sua massa territorial, escudada em considerável dispositivo militar, é a potência regional de presença mais marcante entre o Extremo Oriente e os países árabes do Golfo. Como potência emergente, na fronteira meridional da China (esta última tida por muitos como uma próxima superpotência) $)^{2}$, a Índia atrai as atenções de todos os planejadores diplomáticos. Entre as diversas regiões já mencionadas, que incluem as porções central e meridional da Ásia, há relações complexas, por vezes submetidas a grandes tensões, quando não a conflitos armados, e todas mostram acentuado dinamismo político. No Irã vê-se a disputa entre a ala reformista, favorável à aproximação com o Ocidente, e a tendência mais tradicional, nacionalista e islamizante. No Afeganistão observa-se continuada instabilidade, fora de Cabul; o regime afegane pós-Talibã continua necessitando da proteção de forças estrangeiras e da assistência econômica internacional. Na Ásia Central ocorre uma evolução diferenciada, onde as relações com a Rússia ou os Estados Unidos podem ganhar maior relevo, conforme o caso. 
Entre a Índia e a China desenvolve-se uma possível aproximação, em um processo que está longe de ter sido completado. Para o Paquistão, a China é o all-weather friend (outra expressão costumeira), o aliado tradicional e infalível, ${ }^{3}$ ao passo que a Índia é uma incógnita: das turbulentas relações com a Índia surgiram diversos conflitos e, no entanto, ela poderia tornar-se um parceiro econômico da maior importância para o Paquistão.

\section{Interesses ocidentais}

Nesse quadro de interesses e de conflitos, as grandes potências têm motivos de sobejo para projetar suas políticas. Aqui surge um complicador maior para o quadro já complexo do Sul da Ásia, a saber, as diferenças entre as grandes potências, que se manifestaram de forma súbita e aguda a partir da crise em torno do Iraque. Até o fim de 2002, quando ganhou intensidade essa crise, os projetos das grandes potências mantinham linhas gerais que exprimiam um consenso: contenção das tensões indo-paquistanesas; não-proliferação nuclear; cerceamento do desenvolvimento e uso de mísseis; ortodoxia econômica; e liberalismo político, de maneira a alicerçar regimes constitucionais e civis. Para tornar operacional essa visão das relações internacionais, havia um duplo recurso: pressões diplomáticas de monta, sob a forma da promoção de instrumentos bilaterais, entre eles o Tratado sobre a Não-Proliferação de Armas Nucleares (TNP); e a aplicação de sanções, que podiam ser bilaterais ou coletivas. As sanções conferiam força não desprezível a essas políticas, ao passo que tratados e resoluções da ONU as associavam às noções de consenso e legitimidade.

O conflito no Afeganistão minou a política de sanções. Os Estados Unidos e seus aliados precisavam do apoio do Paquistão, sem o qual não seria possível selar a fronteira afegane nem derrotar o Talibã. As sanções foram suspensas após a fase de definições e alinhamentos de setembro-outubro de 2001. Entretanto, mantinha-se a unidade essencial de políticas das potências ocidentais para o Sul da Ásia. As grandes potências continuavam a exigir a adesão de Islamabade ao TNP e ao Tratado de Proibição Total de Testes Nucleares (CTBT), assim como continuavam a esperar seu entendimento com Nova Délhi. Dentro desses mesmo critérios, exigiam do Paquistão que não intercambiasse tecnologia nuclear nem de mísseis com outros países. Também exigiam que o Paquistão se abstivesse de fornecer meios materiais à insurreição na Cachemira indiana ou de apoiar movimentos da jihad no exterior.

A crise iraquiana introduziu nova e poderosa perturbação nesse quadro consensual. Na verdade, introduziu uma alteração fundamental, ao provocar a ruptura da unidade das grandes potências. O Paquistão havia encontrado uma posição aparentemente segura, ao se alinhar com as potências ocidentais em 2001: obtinha assistência econômica, com o fim das sanções; protegia suas bases 
nucleares, apesar da insistência formal das grandes potências no TNP e no CTBT; e evitava que a coligação internacional antiterror, dirigida contra os anteriores aliados paquistaneses do Talibã, concedesse carta branca a Nova Délhi, em seu confronto crônico com Islamabade. Dado do maior relevo, para o governo paquistanês, as potências ocidentais reconciliavam-se com o regime militar em Islamabade, antes objeto de sanções específicas, aplicadas quando da derrubada do Primeiro Ministro Nawaz Sharif, em 1999.

Com a divisão entre as grandes potências, em função da crise iraquiana, e das conseqüentes disputas no Conselho de Seguranca da ONU, o Paquistão foi chamado a se definir. O Primeiro Ministro Zafarullah Jamali e o Ministro Khurshid Kasuri, dos Negócios Estrangeiros, receberam telefonemas de dirigentes dos dois grupos de potências. Também ocorreram visitas de alto nível, efetuadas tanto pelos Estados Unidos quanto pelo Iraque. O país mais influente no Paquistão são os Estados Unidos. Porém a população paquistanesa está contra a guerra. O prestígio da Rússia, da Alemanha e da Franca aumentou de maneira visível, com pronunciamentos favoráveis de dirigentes partidários e artigos na imprensa sobre a atitude desses países. A China, que já dispunha de excelente imagem no Paquistão, foi mais uma vez louvada por não aderir á coalizão voltada contra o Iraque. O governo paquistanês anunciou sua posição contrária à guerra no Iraque, sem entretanto criticar frontalmente os Estados Unidos.

São graves, do ponto de vista paquistanês, as conseqüências da ruptura ocidental para as relações internacionais no Sul da Ásia. Embora o Paquistão não tenha interesse em domínios hegemônicos no quadro das relações globais, conforme o modelo que se convencionou chamar de unipolar, a divisão entre as grandes potências suscita dilemas graves para Islamabade. Esses dilemas afetam políticas essenciais do Paquistão, desde seu plano de soerguimento econômico até as questões de armamentos. É dentro desse quadro de incertezas que se inserem as estratégias ocidentais para a Ásia, e diante desse quadro o Paquistão terá de tomar decisões fundamentais. Suas decisões também estão ligadas a questões igualmente dilemáticas no plano interno, como se verá adiante.

\section{A tradicional aliança do Paquistão com as potências ocidentais}

Diante das questões assinaladas acima, e dos riscos daí decorrentes, como define o Paquistão suas prioridades e seus alinhamentos? Mehrunnisa Ali, em sua introdução ao livro Readings in Pakistan Foreign Policy, assinala certas constantes que a seu ver marcam meio século de política exterior de Islamabade, desde a independência. O primeiro aspecto é a preeminência concedida às relações com os Estados Unidos, no afã de garantir a segurança nacional contra ameaças externas, com a manutenção dos laços especiais entre as elites dirigentes do Paquistão e Washington, através de sucessivas alterações do quadro internacional, 
e apesar de momentos mais frios nas relações bilaterais. O segundo, a primazia concedida à disputa com a Índia em torno da Cachemira, que levou à implantação de esquemas maciços de armamentos, tanto convencionais quanto nucleares. Um terceiro aspecto é a passagem da necessidade de assistência econômica externa, em seguida à independência (processada de tal forma que deixou o Paquistão com necessidades imensas e recursos diminutos), à execução de políticas ligadas a empréstimos do exterior, a tal ponto que a estabilidade de sucessivos governos passou a ser condicionada pelo fluxo de empréstimos administrados pelo FMI e pelo Banco Mundial.

Ainda conforme assinalado por Mehrunnisa Ali, estando o Paquistão encaixado entre a Índia poderosa e hostil e o Afeganistão, pouco amigável (embora nem sempre), Islamabade procurou garantias em alianças com os Estados Unidos. Tratando-se porém de uma aliança entre parceiros desiguais, com interesses muitas vezes divergentes, era inevitável que o Paquistão de tempos em tempos se visse diante de dilemas e de dificuldades. Em particular, no tempo da Guerra Fria, a política dos Estados Unidos para a Ásia, como se via em iniciativas e pactos como a Organização do Tratado do Centro (Cento) e a Organização do Tratado do Sudeste Asiático (Seato), tinha por objetivo maior conter a influência soviética, ao passo que o do Paquistão consistia sobretudo no de evitar pressões, quando não ataques, vindos do exterior. ${ }^{4}$ Isso teria de resultar em atitudes não coincidentes com as dos Estados Unidos, a exemplo das relações com a China. Pode ser acrescentado que em 2001-2003 o Paquistão viu essa dicotomia ser levada a um ponto extremo, com o conflito no Afeganistão, o recrudescimento das tensões com a Índia e o ataque ao Iraque. Acrescente-se ainda que até 2002-2003, antes da crise iraquiana, o Paquistão podia efetuar seus cálculos em função de uma estratégia relativamente unificada das potências ocidentais, ao passo que a partir de então tem sido defrontado com um quadro internacional menos nítido.

\section{Conflitos e negociações que balizam a situação no Sul da Ásia}

Serão indicados a seguir, de maneira esquemática, alguns dos momentos que contribuíram para conformar a situação presente na Ásia Meridional.

1947 - Independência do Paquistão e da Índia. Primeiro conflito entre os dois novos países, com deslocamentos maciços de populações, em condições extremas de violência. A situação da Cachemira permaneceu indefinida.

1965 - Novo conflito indo-paquistanês, em torno da Cachemira, que continuou dividida.

1971 - Terceira guerra indo-paquistanesa. A Índia intervém no Paquistão Oriental, onde a corrente nacionalista obtém a independência de Bangladesh. Prejuízos imensos para o Paquistão, que perde o lugar de mais populoso país islâmico. A Índia conserva 93.000 prisioneiros de guerra do Paquistão. 
1972 - Acordo de Simla, que leva à libertação dos prisioneiros de guerra paquistaneses e consagra a negociação do contencioso indo-paquistanês por meios pacíficos, no âmbito bilateral ou por qualquer outro meio pacífico que as partes indicarem.

1998 - A Índia efetua testes nucleares em maio, sendo seguida, poucos dias depois, pelo Paquistão. As potências ocidentais aplicam sanções sobre os dois países, que têm efeito muito mais pronunciado sobre o Paquistão.

1999 - No início desse ano o Primeiro Ministro Nawaz Sharif e o Primeiro Ministro Vajpayee encontram-se na cidade paquistanesa de Lahore, dando início ao que se espera ser a superação da hostilidade bilateral. Para surpresa geral, ao começar a estação quente, que franqueia os passos nas altas montanhas entre os dois países, grupos de mujahideen (segundo o Paquistão), ou forças paquistanesas (segundo a Índia) tomam posições estratégicas do lado indiano da Linha de Controle que divide a Cachemira: é a "quase-guerra” de Kargil. A Índia ameaça com retaliações mais amplas. O Primeiro Ministro Nawaz Sharif comparece a Washington, onde se encontra com o Presidente Bill Clinton e decide exercer pressão pela saída dos combatentes antiindianos, encerrando o incidente.

12.10. 1999 - O General Pervez Musharraf, Chefe do Estado-Maior do Exército paquistanês, derruba o Primeiro Ministro Nawaz Sharif. Assume o título de Executivo Principal, com poderes excepcionais, inclusive a faculdade de efetuar modificações na Constituição de 1973. Essa faculdade é reconhecida pela Corte Suprema do Paquistão, dentro de limites, e com a ressalva de que eleições gerais deverão ser efetuadas até outubro de 2002, para o retorno ao regime civil e parlamentar. O General Musharraf eventualmente assumiu a Presidência da República.

2001 - Encontro de cúpula entre o Presidente Musharraf e o Primeiro Ministro Vajapyee, em Agra. O encontro termina de maneira acrimoniosa, sem qualquer êxito. Em dezembro do mesmo ano, o Parlamento indiano sofre atentado. Nova Delhi acusa Islamabade, que devolve as acusações. A Índia desloca efetivos numerosos para a área limítrofe com o Paquistão, que toma medida simétrica; dentro em breve cerca de um milhão de soldados tomam posições de ambos os lados da LoC e da fronteira comum, numa escalada de tensões que causam graves preocupações junto às potências ocidentais. Ao longo de 2002 essas forças retornaram aos poucos a suas posições em tempos de paz.

2002 - O Presidente Musharraf realiza plebiscito, obtendo a prorrogação de seu mandato. Ainda com as funções de Executivo Principal, determina modificações constitucionais que fortalecem o papel da Presidência e limitam as faculdades do Parlamento e do Primeiro Ministro, nos termos da Legal Framework Order (LFO). Em outubro são realizadas eleições gerais, que dão maioria simples à Liga Muçulmana do Paquistão(PML-Q), tendência favorável a Musharraf. Com 
seus aliados, a PML-Q conquista a Mesa da Assembléia Nacional e assegura a escolha do Primeiro Ministro Zafarullah Jamali, pertencente a seus quadros.

2003 - Eleição do Senado, também com maioria da PML-Q e de seus aliados. Nas duas casas do Parlamento a oposição recusa-se a aceitar a incorporação da LFO à Constituição. Até abril de 2003 permanecia o impasse entre oposição e maioria governista. ${ }^{5}$

\section{A inserção paquistanesa no quadro internacional}

O conjunto de considerações precedentes sugere que: a) enquanto havia unidade ocidental, o Presidente Musharraf podia manter uma política de alinhamento que implicava concessões importantes aos Estados Unidos e demais potências, que por sua vez faziam concessões ao Paquistão, em um quadro relativamente estável, apesar da oposição e das críticas de consideráveis setores internos; b) a divisão das grandes potências, sobretudo entre os Estados Unidos e o núcleo “duro”, ou mais coerente, da Europa eliminou o caráter óbvio e seguro da opção em matéria de relações internacionais, tal como vista pela direção paquistanesa, não sendo mais possível um alinhamento geral, sem dilemas, nem mesmo ao custo de concessões importantes; c) a passagem do regime militar a um novo regime parlamentar e civil, justamente no período entre outubro de 2002 e março de 2003, quando a crise em torno do Iraque criou divisões que eliminaram a possibilidade de um alinhamento não dilemático do Paquistão, tornou ainda mais difícil a opção sobre o tipo de alinhamento a ser adotado: ganhou nova força a oposição ao anterior alinhamento com os Estados Unidos, nas ruas e na imprensa, sem falar em setores expressivos do aparelho estatal, com inclinação pela solidariedade islâmica e pela resistência a todo hegemonismo externo; inclinação que coincide com os partidos de orientação islâmica ou nacionalista, que se encontram fora do governo, porém em ascensão.

O alcance dessas questões pode ser avaliado ao se analisarem as relações do Paquistão com diferentes países e centros de poder. Nesse âmbito, cabe destacar as relações com o Afeganistão, os Estados Unidos, outras potências ocidentais, a China e a Índia.

\section{Relações com o Afeganistão}

As relações afegane-paquistanesas passaram por uma mudança radical, após os atentados de setembro de 2001 e a decisão norte-americana de atacar o regime do Talibã. Até então, o governo paquistanês mantinha a esperança de ver o Talibã controlar a totalidade do território afegane. Após sua expansão rápida, a partir de 1994, que levou ao controle das cidades de Kandahar, Herat, Cabul e Mazar-e-Sharif - ou seja, todos os principais centros urbanos do Afeganistão - só 
permaneceram fora do controle do Talibã uma estreita faixa junto a repúblicas da Ásia Central e o Vale do Panjsher, onde se mantinha a principal força de resistência aos fundamentalistas, a chamada Aliança do Norte, com seu núcleo militar composto por tadjiques. As áreas em poder de resistentes tadjiques e uzbeques, estes últimos dirigidos pelo General Dostam, eram alvo de repetidas ofensivas do Talibã, que, segundo a Aliança do Norte, contava com o apoio material do Paquistão. Os sucessivos governos paquistaneses, por sua vez, declaravam que não tinham qualquer participação no conflito afegane e que sua ação a esse respeito se limitava à esfera diplomática, com propostas de negociação.

O Paquistão, basicamente, propunha negociações entre o Talibã e a oposição dirigida pela Aliança do Norte (que constituía a base militar do regime dirigido pelo Presidente Rabbani, visto pela ONU e pela maior parte da comunidade internacional como o poder legítimo no Afeganistão). Diversas tentativas, todas infrutíferas, foram feitas no sentido de se obter acordo entre o Talibã e a Aliança do Norte, inclusive por meio de reunião em Islamabade. O grupo chamado Seis Mais Dois (Estados Unidos, Rússia e os vizinhos do Afeganistão: Paquistão, Irã, Turcmenistão, Uzbequistão, Tadjiquistão e China) mostrou-se ativo, da mesma forma que a ONU e a Organização da Conferência Islâmica. A idéia geral consistia na formação de um governo de conciliação, amplo e representativo. Esse objetivo esbarrava na falta de interesse do Talibã, que acreditava em sua capacidade de completar o controle sobre todo o território afegane. Ao mesmo tempo em que apoiava as negociações, o Paquistão instava a comunidade internacional a reconhecer o regime do Talibã como poder legítimo no Afeganistão. Apenas três países chegaram a dar esse passo: o próprio Paquistão, a Arábia Saudita e os Emirados Árabes. Islamabade logo tornou-se o principal sustentáculo diplomático do Talibã, no âmbito internacional. Ao contrário do que propunha Islamabade, a ONU impôs sanções ao Talibã. Embora o Paquistão as considerasse injustas, desiguais e contraproducentes, declarou-se formalmente disposto a aplicá-las, por ser membro da ONU. As sanções não proibiam o comércio de produtos civis, e o Paquistão continuou a ser a principal rota do comércio exterior do Afeganistão. Segundo a Aliança do Norte, também continuou a fornecer apoio material e direção tática às ofensivas do Talibã, o que sempre foi negado por Islamabade.

O regime do Talibã, chefiado pelo Mulá Omar, havia concedido abrigo a Osama bin Laden, principal dirigente da Al-Qaida, que os Estados Unidos acusavam de haver concebido e executado os atentados de setembro de 2001. Para fazer a guerra aos comandados de Omar e de bin Laden, os Estados Unidos exigiram o apoio do Paquistão, não sob a forma de tropas, mas de concessão de informações (considera-se que as informações sobre o Talibã e bin Laden, nas mãos do InterServices Intelligence do Paquistão, conhecido pela sigla ISI, fossem incomparáveis), do uso de bases, de facilidades logísticas e da abertura de um corredor aéreo (o Afeganistão é um país isolado do mar, que pode ser alcançado mais facilmente 
através do Irã, do Paquistão e de algumas repúblicas da Ásia Central; os Estados Unidos obtiveram suas formas mais importantes de acesso através do território paquistanês e do Uzbequistão, sendo impensável a utilização do espaço iraniano). O Paquistão tentou evitar o dilema entre o abandono de seu aliado afegane e a hostilidade dos Estados Unidos, enviando missões a Kandahar, capital de fato do Talibã, inclusive sob a chefia de seu Ministro do Interior. Entretanto, não conseguiu persuadir o Talibã a entregar bin Laden. Em vista disto, o General Musharraf, Executivo Principal do regime militar do Paquistão, optou pelo que chamou de "mal menor", a saber, o alinhamento com os Estados Unidos. Dessa forma, evitava riscos mortais para o Paquistão, entre eles um ataque seletivo (ou "cirúrgico”) contra suas instalações nucleares, a carta branca do Ocidente a possível expedição punitiva da Índia e a paralisia do comércio exterior (a moratória da dívida externa só podia ser evitada pela renegociação constante dos compromissos com o FMI e os credores ocidentais, e as reservas paquistanesas em moedas fortes só cobriam o correspondente a algumas semanas de importações). ${ }^{6}$

A segurança do Paquistão estava mantida, fato reiterado inúmeras vezes pelo governo do Presidente Musharraf, para contestar seus críticos nacionalistas e os partidários dos movimentos islâmicos. Ainda em 12.04.2003 declarou o Marechal Kaleem Saadat, Chefe do Estado-Maior da Aeronáutica, que as decisões de longo alcance então tomadas pelo governo Paquistão esvaziaram as manobras de seus inimigos. Para Saadat, hoje o mundo inteiro vê o Paquistão como um país amante da paz, com um papel importante na ONU. Em suas palavras, "Durante o período tumultuado após 11 de setembro, nossos adversários tentaram explorar a situação em seu favor, porém em virtude de nossas decisões audazes e de longo alcance, fracassaram em seu intento de nos prejudicar ou de nos isolar da comunidade das nações". ${ }^{7}$ O preço pago por Islamabade foi a perda de seu aliado em Cabul e Kandahar e o fim do sonho de ser a potência mais influente no Afeganistão, projetos que lhe confeririam profundidade estratégica, em caso de novo conflito com a Índia. Por outra parte, Hamid Karzai, o presidente apoiado pelos Estados Unidos, que assumiu o poder no Afeganistão, tem mantido relações amistosas com Islamabade, apesar dos primeiros sinais negativos dos dirigentes da Aliança do Norte, que passaram a integrar a cúpula do novo governo afegane. O Paquistão pode manter seu projeto magno de obter a construção de gasoduto entre as jazidas turcmenas e o centro industrial de Multan, em território paquistanês, através do Afeganistão; o gasoduto, caso efetivamente construído, proporcionará energia a baixo preço para a indústria paquistanesa e realçará a importância geopolítica de Islamabade, como canalizadora dos recursos da Ásia Central. Ao mesmo tempo, impediu a ascensão excessiva da influência indiana em Cabul, inicialmente favorecida pelos ministros oriundos da Aliança do Norte, em detrimento de Islamabade. 
Ainda que vendo sua influência drasticamente reduzida no Afeganistão, este último continua sendo um fator de primeira importância na política externa do Paquistão.

\section{O movimento pendular nas relações entre Paquistão e Estados Unidos}

A presença mais importante nas considerações paquistananesas em matéria de política externa é a dos Estados Unidos. Não se trata de presença uniforme ou tranqüila. Ao contrário, tem sido marcada por avanços e recuos, por fases de pouco interesse por parte dos Estados Unidos, ou de subordinação a outras prioridades, assim como períodos de desconfiança mútua, e até mesmo de imposição de sanções por Washington. O Paquistão responde com a aproximação com outras potências, nas fases de afastamento dos Estados Unidos, ou pela colaboração intensa com Washington, quando esta última propõe o estreitamento dos laços bilaterais. Em uma coisa, entretanto, o Paquistão não cede, qualquer que seja a atitude dos EUA: na manutenção do cerne de sua política externa, que compreende a questão da Cachemira e as medidas de defesa, entre elas o desenvolvimento de sistemas de mísseis e armas nucleares.

As relações entre Paquistão e Estados Unidos, portanto, descrevem um movimento pendular, de conseqüências consideráveis tanto para Islamabade quanto para toda a situação da Ásia Meridional, com reflexos sobre o resto do mundo. A atitude do Paquistão em relação aos Estados Unidos tende a ser constante, com a conhecida disposição de manter ampla gama de colaboração e de atender uma série de exigências norte-americanas. Os Estados Unidos, entretanto, conferem um movimento pendular às relações com o Paquistão, em função de suas políticas do momento. Entre 1979 e 1989, a fim de obter a saída das tropas soviéticas do Afeganistão, bem como de conseguir o isolamento dos governos de esquerda em Cabul, os Estados Unidos cultivaram Islamabade, aceitando o regime ditatorial do General Zia ul-Haq e tolerando a política nuclear do Paquistão. Em 1990, após a saída das forças soviéticas, os Estados Unidos aplicaram sanções a Islamabade, em função de seu programa nuclear, o que causou profundo ressentimento no Paquistão. Apesar das sanções, os Estados Unidos mantiveram relações tão cordiais quanto possível com Islamabade, ainda que restringissem drasticamente as vendas de armas, o que acentuou o desequilíbrio entre o Paquistão e a Índia, em matéria de armamento convencional. Em 1999, com a derrubada do Primeiro Ministro Nawaz Sharif pelo General Pervez Musharraf, que assumiu a chefia do governo, os Estados Unidos aplicaram novas sanções, a título de represália pela queda do regime democrático. Entretanto, após setembro-outubro de 2001, quando Islamabade rompeu com o Talibã e apoiou a campanha norte-americana no Afeganistão, Washington suspendeu a aplicação de sanções e retomou a assistência econômica, além de procurar conter a Índia, em momentos de confronto mais 
grave com o Paquistão. Continua a colaboração entre Islamabade e Washington no que diz respeito ao Afeganistão, ao Talibã e à Al-Qaida, porém o governo paquistanês, diante da intensa oposição interna, teve de se distanciar da política norte-americana em relação ao Iraque. Os Estados Unidos, por sua vez, em 2003, aplicaram sanções ao laboratório paquistanês KRL (Khan Research Laboratories). Ao mesmo tempo, porém, assinaram acordo que confere importantes vantagens econômicas ao Paquistão. Essas questões serão examinadas a seguir.

\section{A presente colaboração entre Paquistão e Estados Unidos}

O que assinala as relações entre Paquistão e Estados Unidos, no presente momento, é a colaboração, associada a importantes concessões de lado a lado. Para os Estados Unidos, isso implica certo dispêndio e não pequeno desvio da ideologia oficial, com suas importantes implicações internacionais. Também dificulta a satisfação das pretensões da Índia, que no entanto correspondem a elemento de relevo na estratégia norte-americana para a Ásia. Para o governo paquistanês, é fonte de desgaste considerável perante a oposição nacionalista e amplos setores da opinião pública.

A fase atual da colaboração bilateral teve início em 2001, com a crise do Afeganistão, que pode ser vista como um divisor de águas na política paquistanesa. O governo paquistanês espera importantes vantagens econômicas de sua cooperação com os Estados Unidos. Em março de 2003 representantes dos dois países firmaram em Islamabade documento sobre cancelamento de parcela importante da dívida paquistanesa com os Estados Unidos. Na ocasião, disse a Embaixadora dos Estados Unidos que a redução da dívida (debt relief) era apenas um elemento de um pacote de assistência, envolvendo diversos aspectos, e bilhões de dólares, que seu país estava proporcionando ao Paquistão. ${ }^{8}$ Formalmente, o ato assinado em março cancelava dívidas da ordem de 200 milhões de dólares, cujo pagamento estava previsto ao longo de três décadas, e que com os respectivos juros chegariam a um bilhão de dólares. No orçamento para o ano de 2004, o governo norte-americano inseriu despesas de 395 milhões de dólares com a assistência ao Paquistão. O significado dessas cifras é melhor avaliado quando se tem em mente que as exportações do Paquistão perfazem cerca de dez bilhões de dólares ao ano. O Ministro Shaukat Aziz, principal dirigente paquistanês no domínio econômico, que estava presente à cerimônia, declarou que os Estados Unidos estavam proporcionando cerca de três bilhões de dólares de assistência ao Paquistão, em resposta ao apoio sem vacilações do governo paquistanês à luta contra o Talibã e a Al-Qaida. ${ }^{9}$ Essa cifra inclui um bilhão de dólares de debt relief, transferências, novos empréstimos e garantias fornecidas pelo Eximbank.

A imagem positiva gerada junto às grandes potências pela adesão à luta contra o Talibã também resultou em apoio econômico por parte de outros países. 
O Japão, que antes havia aplicado sanções econômicas ao Paquistão, em virtude dos testes nucleares de 1998, renegociou em 2003 a dívida consolidada de 4,5 bilhões de dólares, por um período de 38 anos, a baixas taxas de juros. Foi o décimo sexto acordo bilateral firmado nos termos estabelecidos no âmbito do Clube de Paris (Agreed Minutes of the Paris Club), em 13.12.2001, em um total de 12,5 bilhões de dólares. Entre os credores do Clube de Paris, a Dinamarca e o Reino Unido cancelaram o débito a ser pago, nos valores respectivos de 18,4 e de 29,5 milhões de dólares. ${ }^{10}$

\section{As reservas de círculos nos Estados Unidos}

Aos críticos, no Paquistão, que vêem na largueza dos Estados Unidos um fenômeno passageiro, a se dissipar assim que cessar o papel paquistanês no combate ao Talibã e à Al-Qaida, respondem os dirigentes norte-americanos que o novo relacionamento bilateral tem caráter permanente e será aprofundado. Conforme disse a anterior Embaixadora dos Estados Unidos em Islamabade, é preciso olhar para o futuro, não para o passado. Muitos observadores norte-americanos, entretanto, relativizam a nova aliança. Intervenções de estudiosos e especialistas em assuntos da Ásia Meridional, no seminário “The state of Pakistan”, reunido na Paul Nitze School of Advanced International Studies, da Universidade Johns Hopkins, nos Estados Unidos, um dia após as sanções contra o KRL, na síntese constante de artigo de Anwar Iqbal, “descreveram o Paquistão como um país dotado de importância geopolítica, porém politicamente fraco, que deve enfrentar sérios problemas [...] potencialmente catastróficos”.

Diversas intervenções, no mesmo seminário, lançaram dúvida sobre a solidez da aliança paquistanesa com os Estados Unidos. Conforme as declarações atribuídas a George Perkowich, Vice-Presidente de estudos no Carnegie Endowment for International Peace, o Paquistão representa perigo maior para a não-proliferação que o Iraque, assim como desafio significativo para a política dos Estados Unidos. Além das questões de guerra atômica e da transferência de tecnologia nuclear, a fragilidade da estrutura econômica e política do Paquistão representa ameaça para a segurança do armamento nuclear detido pelo país; caso emergisse um governo islâmico de atitudes militantes, no Paquistão, seja através de eleições, seja através de um golpe, isso faria desse país um Estado muçulmano extremista, nuclearmente armado.

Ainda segundo relatado por Iqbal, Christophe Jaffrelot, diretor do Centre d'Etudes et de Recherches Internationales, um think tank em Paris, afirmou que os mujahideen da Cachemira estavam de volta às atividades de costume. Esses grupos seriam também responsáveis por ataques a alvos ligados ao Ocidente, tais como o Consulado dos Estados Unidos em Karachi, em 2002. Para Jaffrelot, os grupos da jihad certamente foram prejudicados pelas políticas de Musharraf após 
janeiro de 2002, porém voltaram a se organizar, fundando novos movimentos. Em outras intervenções, no seminário acima referido, foi dito que:

- bolsões relevantes, no Paquistão, opõem-se à aliança com Washington, o que lança dúvidas sobre a colaboração na luta contra o terror;

- os partidos religiosos crescem no Paquistão, e no passado recente exerceram influência de peso, ao apoiar o Talibã e a Al-Qaida;

- os partidos religiosos mostraram pronunciado crescimento nas eleições gerais de outubro de 2002;

- acredita-se que milhares de membros da Al-Qaida tenham encontrado refúgio no Paquistão;

- elementos dentro das forcas armadas e das agências de informação do Paquistão mantiveram conexões com o Talibã, a Al-Qaida e outros grupos empenhados em ações violentas, alguns deles empenhados em minar o controle da Índia sobre sua porção da Cachemira.

Exprimindo os dilemas da situação, que existem não só para o Paquistão, como também para os Estados Unidos, disse Anatol Liven, senior associate no Carnegie Endowment, que Washington deve manter seu engajamento em relação a Islamabade; o Paquistão é um importante parceiro estratégico e a colaboração com os Estados Unidos deve continuar, caso se queira conter o "terrorismo" originado em território paquistanês. ${ }^{11}$

\section{A oposição nacionalista à colaboração com os Estados Unidos}

Como foi visto, no âmbito dos governos são freqüentes e enfáticas as declarações sobre interesse de ambos os lados na colaboração, em que pesem as recentes sanções aplicadas ao KRL; porém entre as correntes de opinião são comuns a desconfiança, quando não a hostilidade, e as recriminações. É o que se vê não apenas entre os think tanks norte-americanos, mas também entre os partidos nacionalistas no Paquistão. As críticas e propostas de se por término à colaboração com os Estados Unidos têm origem tanto em questões relacionadas diretamente com o Paquistão quanto com aquelas que dizem respeito à Ummah muçulmana, em particular à Palestina e ao Iraque.

Entre as muitas demonstrações de protesto contra o ataque ao Iraque, no Paquistão, a Aliança dos Partidos religiosos Muttahida Majlis-e-Amal (MMA) efetuou suas million-men marches nos grandes centros urbanos de Karachi (a maior cidade do país), Lahore (capital da província mais populosa), Rawalpindi (contígua a Islamabade) e Peshwar (principal porta de acesso ao Afeganistão), além de locais significativos como a cidade industrial de Multan. Nesta última, em 04.04.2003, os oradores exigiram que o Presidente dos Estados Unidos e o Primeiro Ministro do Reino Unido fossem julgados por uma corte internacional, por lançarem ataque contra um país soberano e por perpetrarem o genocídio; e denunciaram a 
"cruzada" - termo de conotações sinistras, nos países islâmicos - de George Bush no Afeganistão e no Iraque. Não apenas os maulanas (sacerdotes islâmicos) da MMA falaram no comício de Multan; também o veterano político Nawabzada Nasrullah Khan, principal dirigente da coalizão liberal ARD (Aliança para a Restauração da Democracia), afirmou que a série de million-men marches da MMA mostrava que o povo rejeitava a política do governo paquistanês a respeito de questões vitais, tais como a guerra contra o Iraque (segundo os manifestantes, o governo paquistanês deixou de apoiar com firmeza o Iraque, para não desagradar os Estados Unidos, tese rejeitada pelos círculos oficiais). A conexão entre a oposição à aliança com os Estados Unidos e o movimento pelo fim do regime autoritário no Paquistão foi ressaltada pela exigência do chefe da ARD de que se suprimisse a LFO. ${ }^{12}$ Em Quetta, capital da Província do Baluquistão, outro portal de acesso ao território afegane, nova demonstração-monstro manifestou a oposição à guerra contra o Iraque e à colaboração com os Estados Unidos. ${ }^{13}$

A oposição à política norte-americana em relação aos países islâmicos chegou a um ponto em que se tornou elemento de definição das correntes nacionalistas. Ao que parece, todo futuro apelo ao eleitorado paquistanês levará em conta esse dado. O ANP (Awami National Party), que perdeu suas tradicionais posições para a MMA, na Província Fronteira do Noroeste (NWFP), resolveu marcar sua presença e também organizou comício de amplas proporções em Peshawar. Na ocasião, declararam seus oradores que:

- a guerra contra o Iraque, dirigida pelos Estados Unidos, não é uma guerra entre o Islã e os infiéis (kuffar), mas uma guerra contra a humanidade;

- deve-se condenar o papel do governo paquistanês a esse respeito;

- a guerra acabaria em poucos dias, se os governos árabes parassem de vender petróleo aos Estados Unidos ;

- como nada fazem para se opor ao domínio norte-americano, os Estados Unidos virão atacar cada um deles, escravizando nações inteiras;

- os dirigentes árabes devem ser criticados, por sua atitude em relação à guerra, e o Papa João Paulo II deve ser louvado;

- é inútil esperar ação efetiva da ONU ou da OIC (Organização da Conferência Islâmica, que congrega cinqüenta e seis países);

- a China e a Rússia deveriam levantar-se e procurar aliados, para impedir as injustiças cometidas pelos Estados Unidos ;

- convidam-se a França, a Alemanha, a Rússia e a China a criar uma nova ONU, com outro Conselho de Segurança, para impedir que os Estados Unidos ataquem os países mais fracos.

Também falando nessa ocasião, disse o ex-ministro federal Haji Ghulam Ahmad Bilour que era deplorável a atitude dos dirigentes muçulmanos, mudos diante do ataque ao Iraque. Ele considerou os mulás (outro título dado aos 
sacerdotes islâmicos) culpados por estimularem tanto a supressão dos patãs no Afeganistão quanto as forças que levaram à desagregação da União Soviética, assim destruindo a balança mundial do poder e levando à miséria tantos muçulmanos. ${ }^{14}$ Ao falar dessa maneira, Bilour contrastou o universalismo esclarecido do ANP e o que considera como espírito sectário e atitudes contraproducentes dos partidos que integram a MMA. Trata-se, naturalmente, de discurso com objetivos eleitorais, em uma província que a MMA acaba de arrebatar; entretanto, é significativo que em comício dessas proporções, um orador possa apontar o papel positivo da União Soviética e criticar a ação dos fundamentalistas no Afeganistão, isto no Paquistão, e ainda mais em Peshawar, onde as críticas aos soviéticos costumam constituir artigo de fé. Que o orador possa ter falado dessa maneira por certo mostra como a guerra contra o Iraque e outras políticas dos Estados Unidos, sobretudo em relação à Palestina, têm contribuído para mudar a opinião paquistanesa. Isso também tem levado à publicação de numerosos textos na imprensa paquistanesa que refletem desencanto com o papel de muitos governantes árabes. ${ }^{15}$

O governo paquistanês deu-se conta da indignação suscitada nos mais diversos setores do país pelo ataque contra o Iraque e negociou com a oposição, no Senado, o texto de resolução sobre a matéria. Os meios da oposição, sobretudo os senadores da MMA, desejavam resolução que condenasse os Estados Unidos. Entretanto, com sua maioria no Senado, o governo conseguiu texto que "deplorava fortemente" (strongly deplores, conforme a expressão utilizada) a guerra. Pela mesma resolução, o Senado exigiu o término imediato das hostilidades. ${ }^{16}$

\section{Perspectivas da ação dos Estados Unidos e do Reino Unido no Sul da Ásia}

Após conflito no Iraque, a política dos Estados Unidos para o Sul da Ásia parece encaminhar-se para alguma forma de mediação que não será destituída de custos para o Paquistão. A política de Washington para a região deverá manter certos critérios fundamentais, anunciados e reiterados pela diplomacia norteamericana, entre eles as gestões de alto nível para se evitar um conflito indopaquistanês, a limitação do apoio de Islamabade aos movimentos irredentistas na Cachemira e, tanto quanto possível, o encorajamento ao diálogo entre Índia e Paquistão. A isso pode ser acrescentada a tentativa - dentro de certos limites de deter os impulsos que possam conduzir à proliferação nuclear.

Por certo as considerações sobre o controle do Iraque e a situação no Oriente Médio terão precedência sobre os problemas do Sul da Ásia, mas o interesse dos Estados Unidos nesses últimos será mantido, conforme atestam as declarações de Colin Powell, em entrevista a The New York Times. Segundo Powell, ele espera abordar a questão das relações indo-paquistanesas, que são parte de uma broader agenda, quando a do Iraque houver sido enquadrada. Os 
Estados Unidos não desejam ver a situação no Sul da Ásia reverter ao estado em que estava um ano atrás (no início de 2002, as tensões entre a Índia e o Paquistão eram fortes o bastante para que as grandes potências temessem um novo conflito na região, conforme assinalado acima). Powell ressaltou também a capacidade dos Estados Unidos de exercerem efeito moderador na Ásia Meridional: "A hell of a lot went into preventing an Indo-Pakistani nuclear war." ${ }^{17}$

Apresenta-se a questão de saber qual a direção a ser tomada pelas gestões dos Estados Unidos. O Paquistão deseja a abertura de negociações com a Índia, a respeito da Cachemira e dos demais problemas bilaterais. Deseja igualmente a implementação das resoluções da ONU sobre o território disputado, inclusive no que diz respeito à sua autodeterminação. A Índia deseja o fim da insurreição na Cachemira, a seu ver uma série de atentados orquestrados por movimentos apoiados em território paquistanês. Nesse mesmo sentido opinam os Estados Unidos e também o Reino Unido, seu aliado mais próximo. Conforme declarado pelo Foreign Secretary Jack Straw, em entrevista à televisão em Nova Délhi, os dois países tem solicitado ao Paquistão que contenha o fluxo de militantes muçulmanos que entram na porção indiana da Cachemira. A Cachemira teria o potencial de causar novo conflito indo-paquistanês, o que realça a preocupação com a "increasing evidence of infiltration across the Line of Control from Pakistan to India". ${ }^{18}$

Compreendem-se portanto os termos graves do editorial do diário The Nation, de Islamabade:

The USA's refusal to accept [...] Sinha's [o ministro do exterior da Índia] contention that the pernicious new US doctrine of pre-emption applies to Kashmir and thus to Pakistan, is to be welcomed. [...] However, this should not be viewed with too much complacence. The recent US-UK joint declaration places Kashmir on the joint agenda for the post-Iraq world. This does not necessarily bode well for Pakistan, because the US regards India as its regional strategic partner [...] [e] Pakistan $[\ldots .$.$] merely a temporary tactical ally. { }^{19}$

É verdade que Colin Powell rejeitou todo paralelo entre o Iraque e o Sul da Ásia. Conforme reproduzido pela imprensa paquistanesa, Powell teria dito:

I stay in very close touch with the authorities in both Pakistan and India [...] We do have a very difficult and dangerous situation with respect to actions across the Line of Control and the United States will remain engaged [...] But we don't believe there is need now for any military action of any kind. ${ }^{20}$

Nos termos dessa declaração, o futuro parece incerto; e, conforme observado acima, o Ministro Sinha havia afirmado existir fundamento para preemptive strike contra o Paquistão, tanto por parte da Índia quanto dos Estados Unidos. O Ministro George Fernandes, titular da pasta indiana da Defesa, teria 
prestado declaração no mesmo sentido: “There are enough reasons to launch such strikes against Pakistan, but I cannot make public statements on whatever action that may be taken." ${ }^{21}$ Declarações, mesmo drásticas, nem sempre exprimem intenções reais. Por vezes há simplesmente a intenção de enviar sinal ao lado oposto, ou até mesmo ao eleitorado. Ainda assim, afirmações sobre pre-emptive strikes não são feitas todos os dias, em qualquer país do mundo.

O governo paquistanês ressalta tanto seu crédito internacional quanto sua capacidade de autodefesa. Lembra que tem sido aliado relevante das potências ocidentais no combate ao terrorismo e cita os ganhos efetuados pelo sistema nacional de pesquisa, desenvolvimento e instalação de meios estratégicos. Essas noções têm sido reiteradas por diversas autoridades paquistanesas, inclusive pelo Presidente Musharraf, em sua alocução perante a guarnição militar de Peshawar, em 11.04.2003.22

Muitos observadores paquistaneses, entretanto, ressaltam o que consideram como elementos desfavoráveis para seu país. O Coronel Masud Akhtar Sheikh, da reserva do Exército paquistanês, insta seus compatriotas a não esquecerem que: o Paquistão, potência nuclear, é sore in the eyes dos Estados Unidos e da Índia; a Índia é muito mais importante para os Estados Unidos que o Paquistão, no esquema preparado por Washington após o desaparecimento da União Soviética; os Estados Unidos fariam qualquer coisa para aplacar a Índia, inclusive a desnuclearização forçada do Paquistão; a Índia vem instigando Washington contra o Paquistão, manipulando o assim chamado terrorismo transfronteiriço e não poupará esforços para difundir rumores sobre um suposto comércio nuclear entre Islamabade e inimigos dos Estados Unidos. ${ }^{23}$

Alerta semelhante foi soado por um outro articulista influente, o ex-senador e ex-ministro Shafqat Mahmood: "Indians are the strategic partners and we are only tactical partners for the conflict in Afghanistan and for flushing out al-Qaeda. Tactics are temporary, strategy has depth and duration.”24

Um ponto de vista diferente, mas que também lança um alerta, é o de Shireen Mazari, Diretora-Geral do Instituto de Estudos Estratégicos de Islamabade, talvez o mais prestigioso dos think tanks paquistaneses. Para a Diretora-Geral do Instituto, que publica comentários freqüentes na imprensa paquistanesa, "It is not an issue of being 'next' in terms of US military action. It is an issue of coming under increasing US pressure to 'fall in line' with US policy aims in the region.” $\mathrm{O}$ eventual enquadramento do Paquistão incluiria os seguintes aspectos: permitir a intervenção norte-americana em assuntos internos, modificando os dados da vida política paquistanesa; limitação da capacidade nuclear do Paquistão, já que sua erradicação pura e simples não seria possível; aceitação, por Islamabade, da situação presente na Cachemira; abandono de qualquer noção de laços estratégicos com o Irã; e aceitação da hegemonia regional da Índia. Ao mesmo tempo, os Estados Unidos exigiriam a continuação de seu acesso irrestrito às estruturas do 
Estado paquistanês, a pretexto de travar a guerra contra o terrorismo. Ao contrário do que diz o governo paquistanês, Shireen Mazari afirma que Islamabade pouco recebeu de sua colaboração com Washington, a não ser críticas, ameaças e sanções. O maior risco, para ela, vem do comprometimento da soberania decorrente de possíveis operações de hot pursuit no rastro de combatentes suspeitos de integrar o Talibã ou a Al-Qaida, a partir do território afegane, como já foi anunciado por porta-vozes norte-americanos, e a seguir desmentido, com certa ambigüidade. Segundo ela, a melhor defesa para o Paquistão, nesse quadro inseguro, residiria em proactive multilateralism, em vez de fearful and defensive unilateralism. ${ }^{25}$

\section{Papel de outras potências européias}

Até a crise no Iraque, havia relativa unidade de pontos de vista dos Estados Unidos, do Reino Unido, da França, da Alemanha e da Rússia quanto ao Paquistão, mesmo que houvesse diferenças no que diz respeito à política dessas potências em relação à India. Todas elas mostravam interesse na diminuição das tensões indo-paquistanesas, bem como no soerguimento econômico do Paquistão, ao mesmo tempo em que exerciam pressões contra o programa paquistanês no domínio nuclear. A imagem da Rússia, da França e da Alemanha ganhou reforço substancial, após a crise no Iraque.

Em contraste com o distanciamento entre Islamabade e Moscou, ao tempo dos regimes de esquerda em Cabul, e à pouca densidade das relações nos anos subseqüentes, a visita do Presidente Musharraf à Rússia, em fevereiro de 2003, foi saudada como sinal de importantes desenvolvimentos, no Paquistão. Os títulos da imprensa paquistanesa foram significativos, a exemplo daquele do artigo "A rare visit stirring up hopes". ${ }^{26} \mathrm{O}$ mesmo pode dizer-se da opinião dos articulistas, tais como Khalid Akhtar: a "soldierly diplomacy" do Presidente Musharraf não produziu resultados de maior significado do lado norte-americano; tampouco será fácil tirar as relações russo-paquistanesas do atoleiro da Guerra Fria, mas a possibilidade de um avanço decisivo é visível, diante dos gestos de boa-vontade de ambas as partes. ${ }^{27}$

As esperanças depositadas na Alemanha e na França eram evidentes, tanto nos artigos e editoriais da imprensa paquistanesa quanto nos discursos de dirigentes partidários em comícios de protesto contra o ataque ao Iraque. Também no seio da elite dirigente do Paquistão era fácil perceber essa atitude. Por ocasião da comemoração em Islamabade dos quarenta anos do Tratado do Eliseu, marco da concórdia franco-alemã dentro do quadro da Europa unificada, verificou-se o comparecimento de cerca de quatrocentas pessoas, entre diplomatas, membros do Parlamento paquistanês, jornalistas e figuras de destaque nos meios profissionais e de negócios. Os discursos dos representantes francês e alemão, com observações contrárias à guerra contra o Iraque, então em curso, eram pontilhados de aplausos. 
Quem acompanha a imprensa paquistanesa dá-se conta da admiração suscitada pelo governo francês, ao manter uma posição independente e contrária à guerra, durante o conflito do Iraque. A imprensa paquistanesa reproduziu constantemente comentários de fontes européias sobre a posição francesa, quando não divulgava seus próprios artigos e editoriais. Em um dos artigos publicados pelo diário Dawn, de Karachi, lê-se esta citação do jornal francês Libération, que no entanto não costuma apoiar o Presidente Jacques Chirac: "Este é seu grande trabalho, o que lhe abrirá os livros de história.” Nos termos do mesmo artigo, Chirac acredita que haja um estado de equilíbrio precário, com uma única superpotência, o que representa ameaça à estabilidadde global. Em um novo mundo multipolar, a Europa teria lugar indiscutível. As tendências à divisão do poder global seriam inevitáveis, como se pode ver com a ascensão da China. Seria então necessário criar uma coalizão com peso suficiente para contrabalançar o papel dos Estados Unidos. ${ }^{28}$

Na opinião pública e entre os formadores de opinião, não há dúvida de que as posições acima expressas granjeiam imenso apoio no Paquistão. Entretanto, não se pode prever ainda em que medida a atitude da França, da Alemanha e da Rússia, separada das posições dos Estados Unidos, em questões ligadas ao Oriente Médio, influenciarão a política paquistanesa. Mas seu potencial é significativo, sobretudo à medida em que o novo regime parlamentar do Paquistão se afastar do anterior período autoritário, e que essa evolução incorpore maior influência da opinião pública e dos partidos nacionalistas.

\section{Questão da não-proliferação no Sul da Ásia}

Os observadores paquistaneses temem pressões dos Estados Unidos não apenas em matéria de acomodação com a Índia. A questão da não-proliferação é essencial. Os Estados Unidos, depois da campanha contra o Iraque, por certo insistirão no desarmamento de outros Estados periféricos. No caso da Índia, ao contrário, os sinais já emitidos sugerem aceitação tácita do programa indiano de armamentos, como se deduz das missões de alto nível de Washington a Nova Délhi, para a ampliação da cooperação militar. Mas a Índia tem o papel especial, aos olhos dos Estados Unidos, de representar possível contrapeso à influência chinesa no Oriente; de outra forma, a China poderia desfrutar do papel isolado de grande potência em sua região específica, projetando também sua influência sobre a Ásia Central e Meridional. O Paquistão atua como aliado da China, e a influência que ele contribui para diminuir é a da Índia. ${ }^{29}$

Em particular, os Estados Unidos não desejam que o Paquistão dissemine sua tecnologia nuclear. Em pleno conflito iraquiano, e ao longo das tentativas norteamericanas de conter as tensões indo-paquistanesas, Washington aplicou sanções ao KRL, proibindo o comércio entre esta entidade e organizações nos Estados 
Unidos. O KRL, situado em Kahuta, nas cercanias de Islamabade, é o principal laboratório paquistanês empenhado na pesquisa e desenvolvimento de tecnologias relacionadas com armas nucleares. Em abril de 2003 foi anunciada a imposição de sanções ao KRL, alegadamente por ter recebido tecnologia de mísseis da empresa Changgwang Sinyong Corporation, da República Democrática e Popular da Coréia. As sanções não foram atribuídas ao programa nuclear paquistanês; conforme esclarecido pela Embaixada dos Estados Unidos em Islamabade, elas deviam-se a "specific missile-related transfer", e "do not pertain to any other activity, including nuclear-related ones” ${ }^{30}$.

\section{A amizade sino-paquistanesa}

Em contraste com as relações oscilantes, e por vezes tempestuosas, entre o Paquistão e os Estados Unidos, a amizade com a China é vista como o supremo modelo em Islamabade. A China, conforme já assinalado, é o all-weather friend, fonte de longo e tradicional apoio, sobretudo nas horas difíceis. A ênfase nas relações com a China recai sobre a cooperação diplomática e econômica, embora ela também se estenda ao domínio do material bélico. Quando o Primeiro Ministro chinês Zhu Rongji visitou o Paquistão, a imprensa de Islamabade celebrou com amplas manchetes alguns projetos de grande alcance, a serem conduzidos com apoio da China, a exemplo da construção do porto de Gwadar e da Rodovia Costeira, do aproveitamento das jazidas de carvão de Thar e do reequipamento das ferrovias paquistanesas. Com a visita do Primeiro Ministro Jamali a Pequim, em 2003, o montante do apoio chinês a esses e outros projetos foi cifrado em 2,4 bilhões de dólares, o que incluiu 700 milhões para a ampliação da Pakistan Steel e 800 milhões para uma nova central nuclear em Chashma. ${ }^{31}$ Embora todos esses projetos sejam de grande importância, chama atenção a construção do porto de Gwadar, alternativa ao de Karachi. A Índia havia ameaçado bloquear este último, quando da "quaseguerra” de Kargil; Gwadar situa-se não na direção da Índia, mas na do Irã, mais perto, portanto, do acesso ao Golfo Pérsico, com suas rotas de transporte do petróleo.

Apesar da imagem calorosa das relações com Beijing, elas não podem eclipsar as que o Paquistão mantém com os Estados Unidos. A elite paquistanesa volta-se para o Ocidente e vê as potências ocidentais como garantia última da ordem liberal que lhe interessa, ainda que os dirigentes e comentaristas em Islamabade louvem o êxito do modelo econômico da China. O governo paquistanês também confere peso elevado ao poderio ocidental, sobretudo dos Estados Unidos, que poderia exercer um efeito desestabilizador na Ásia Meridional, caso se alinhasse incondicionalmente com a Índia. Cabe ainda notar que a Índia tem procurado desenvolver suas relações com a China, o que evitaria uma presença excessivamente forte de Islamabade nas cogitações de Beijing sobre o Sul da Ásia. Segundo 
declarações do Ministro Yashwant Sinha, transcritas pela imprensa paquistanesa, a Índia e a China puseram de lado a espinhosa disputa fronteiriça de 1962 para melhor desenvolverem suas relações bilaterais; Nova Délhi agora veria Beijing como um importante vizinho e amigo. ${ }^{32}$

\section{Permanência das tensões indo-paquistanesas}

As tensões entre o Paquistão e a Índia nunca cessaram por completo, desde a traumática independência dos dois países, em 1947. Tradicionalmente mencionam-se três guerras, além de diversas crises, com os intervalos marcados por acordos sob pressão, negociações nem sempre exitosas ou fases de calmaria pouco tranqüila. Em análise recente, entretanto, Ahmad Faruqui vê cinco guerras entre a Índia e o Paquistão, entremeadas de crises e intervarlos tensos nas relações bilaterais: além das guerras de 1947 (pelo controle da Cachemira, cujo destino foi mantido em suspenso pelos acordos coordenados pelo Reino Unido), de 1965 (deflagrada pela disputa em torno do Rann de Kutch) e de 1971 (quando a intervenção indiana levou à divisão do Paquistão, com a conseqüente independência de Bangladesh), um quarto conflito, em 1984, em torno do controle da geleira de Siachen, nos Himalaias (o terreno de luta mais elevado do mundo, e talvez o de menor valor, a não ser simbólico, com seus penhascos e seu campos de gelo), e por fim o de 1999, novamente na Cachemira, com os choques armados na área de Kargil. $^{33}$

Esse último conflito ocorreu no mesmo ano do chamado processo de Lahore, quando o então Primeiro Ministro Nawaz Sharif e o Primeiro Ministro Vajpayee assinaram documento, na cidade paquistanesa desse nome, que deveria levar a negociações sobre o conjunto do contencioso bilateral e talvez à normalização das relações indo-paquistanesas. O confronto armado em Kargil pôs cobro a essa perspectiva. Logo em seguida foi derrubado Nawaz Sharif, assumindo o General Musharraf a chefia do governo. Já à frente do governo paquistanês, Musharraf daria nova oportunidade às negociações bilaterais, na reunião de cúpula de Agra, também com Vajpayee. Entretanto, a reunião terminou em recriminações mútuas ${ }^{34}$, não tendo outro resultado que o de acentuar o caráter pouco abordável do contencioso bilateral.

Desde o fracasso da cúpula de Agra, as relações indo-paquistanesas voltaram ao ponto morto. Islamabade tem insistido na retomada das negociações sobre o contencioso bilateral, porém Nova Délhi condiciona toda iniciativa nesse sentido ao término do que denomina cross-border terrorism, cuja existência é negada pelo governo paquistanês. A situação foi agravada em dezembro de 2001, com o atentado terrorista dirigido contra o Parlamento indiano. A Índia imediatamente acusou o Paquistão, que, entretanto, negou qualquer conexão com o atentado. Em represália, a Índia deslocou grande número de unidades militares 
para a fronteira com o Paquistão e para a LoC. Islamabade tomou medida simétrica, e no primeiro semestre de 2002 as tropas deslocadas por ambos situavam-se em torno de um milhão de homens. O governo paquistanês afirmou que teria de desfalcar as unidades mantidas na fronteira do Afeganistão, que colaboram com os Estados Unidos no rastreamento e captura de grupos remanescentes do Talibã e da Al-Qaida. Os Estados Unidos, preocupados com o afrouxamento da vigilância sobre seus inimigos no Afeganistão, e talvez ainda mais com o risco de conflito indo-paquistanês, efetuaram sucessivos contatos de alto nível, a fim de obter a diminuição das tensões, no que foram acompanhados pelo Reino Unido e outras potências européias.

No segundo semestre viu-se a diminuição das tensões bilaterais, com a retirada da maioria das tropas indianas e paquistanesas para suas posições normais em tempo de paz. Entretanto, sucessivos atentados na Cachemira indiana mantêm as tensões, ressaltadas pelos esporádicos duelos de artilharia através da LoC. O massacre de vinte e quatro indianos na Cachemira, em abril de 2003, constitui o mais recente episódio terrorista até a data, provocando as costumeiras recriminações mútuas entre Islamabade e Nova Délhi. Também no Paquistão ocorrem atentados com freqüência, e a polícia paquistanesa de vez em quando acusa a RAW (Research and Analysis Wing), serviço secreto indiano, de participação nesses episódios. Vez por outra as autoridades paquistanesas apresentam à imprensa indivíduos originários do próprio Paquistão, que teriam sido subornados ou coagidos pela RAW para perpetrarem atentados em território paquistanês.

Novo foco de tensões foi introduzido com a crise em torno do Iraque, quando o ministro do exterior da Índia comparou a situação iraquiana com a paquistanesa. Segundo o Ministro Yashwant Sinha, Nova Délhi tinha maiores motivos para lançar um pre-emptive strike contra o Paquistão que Washington contra o Iraque. O massacre de vinte e quatro hindus na aldeia de Nadimarg teria motivado fresh thinking em Nova Délhi, a respeito do combate ao terrorismo. Mencionando a posse de armas de destruição em massa pelo Paquistão e acusando este último de ser "epicentro" de ações terroristas, disse Sinha: "If these were considerations for a pre-emptive strike against another country, then definitely India has a better case.”35

O governo paquistanês imediatamente contestou o paralelo com o Iraque e reiterou sua confiança na autodefesa. Segundo Khurshid Kasuri, Ministro dos Negócios Estrangeiros, "Our missile defense system is at par with the five major countries in the world". Nessa mesma veia disse Kasuri: "We reject the doctrine of pre-emption. India should not harbour any illusion." ${ }^{36}$

Essas declarações e advertências, por drásticas que sejam, não impedem que se busque a retomada das negociações bilaterais. Quando as especulações sobre pre-emptive strikes atingiam seu ápice, o Primeiro Ministro indiano recolocou 
o jogo na mesa de conversações, ao declarar que seu país estava disposto a negociar com o Paquistão. É verdade que Vajpayee subordinou essa iniciativa ao tão citado fim do "terrorismo transfronteiriço", noção, como se sabe, considerada vazia pelo Paquistão. Ainda assim o Primeiro Ministro paquistanês logo considerou positiva a oferta de Vajpayee. Dando prosseguimento à idéia, afirmou Digvijay Singh, junior minister na Chancelaria indiana: "We are ready the minute Pakistan indicates that it is willing to usher a new era of peace.” Singh disse que as conversações poderiam começar já em junho de 2003, desde que o Paquistão reagisse adequadamente às preocupações indianas. Para tanto, até mesmo uma simples declaração contra a violência, por Islamabade, seria suficiente. ${ }^{37}$

\section{Perspectivas}

A retomada do processo de paz indo-paquistanês mudaria todos os dados políticos e militares para o Sul da Ásia. Como assinalou o dirigente politíco indiano Omar Abdullah, anterior junior minister sob Vajpayee, "If India-Pakistan talks are not initiated sooner rather than later, the American government, after it is free from the war in Iraq, may thrust a solution on Kashmir which may not be in the interest of New Delhi and Islamabad". ${ }^{38}$

Desde a independência do Paquistão e da Índia, as tentativas de resolver a questão da Cachemira têm tido destino semelhante às de resolver o problema da quadratura do círculo: o Paquistão exige a implementação das resoluções da ONU que estabelecem o princípio da autodeterminação, ao passo que a Índia considera a Cachemira como parte integrante de seu território. Cabe indagar se o novo quadro mundial, com as tendências tornadas mais agudas pelo conflito no Iraque, será capaz de introduzir modificações substanciais nas atitudes de Islamabade e de Nova Délhi.

Caso isso não aconteça, as grandes potências continuarão a se defrontar com o quadro perigoso da Ásia Meridional, com dois novos aspectos, que o complicam ainda mais: a divisão que se esboça entre as grandes potências, a respeito do papel protagônico dos Estados Unidos, e a ascensão das correntes nacionalistas no Paquistão. Quanto a este último aspecto, deve ser assinalado que o controle absoluto do Presidente Musharraf sobre as políticas interna e externa do Paquistão chegou ao fim com o retorno ao regime civil, entre outubro de 2002 e março de 2003. Musharraf ainda é a principal personalidade política do país, porém sua capacidade de conservar os alinhamentos externos está ligada à manutenção dos extensos poderes de que dispõe, nos termos da Legal Framework $\operatorname{Order}^{39}$. A oposição rejeita a LFO, a ponto de ter mantido quase paralisado o Parlamento paquistanês, em abril de 2003, com seus prostestos. Caso a LFO venha a ser revogada, ou suas disposições sejam diluídas, tanto o Parlamento quanto os formadores de opinião e as mobilizações partidárias de massa (no 
momento dirigidas sobretudo pelas formações islâmico-nacionalistas) verão sua influência aumentar sobre a política exterior do Paquistão. Abre-se, portanto, um quadro de desdobramentos potenciais de grande importância, para o Sul da Ásia, para as principais potências e para o conjunto da comunidade internacional.

Abril de 2003

\section{Notas}

1 Indo-Pakistani conflict most daunting challenge: Rocca. The Nation. 31.03.2003, p. 12.

2 Ver a análise de Victor SUKUP: A China frente à globalização: desafios e oportunidades. Revista Brasileira de Política Internacional, Brasília, Instituto Brasileiro de Relações Internacionais, Ano 45, n.. 2, 2002, p. 82-113.

3 Rafeh A. MALIK, China An Emerging Great Power: Regional And Global Perspectives, p. 93: "Pakistan is now seeing China as an ally who can be relied upon more than ever before". National Development and Security (Quarterly Journal), Vol IX, n. 2, Winter 2000, p. 83-100. Rawalpindi, Paquistão: Foundation for Research on International Environment National Development and Security:, Paquistão. Mehrunnisa ALI (ed.). Introduction. Readings in Pakistan Foreign Policy, 1971-1998. Karachi: Oxford Univ Press, 2001, p 1-3.

5 Uma justaposição de dados referentes à política interna, com sua sucessão de regimes civis e militares no Paquistão, bem como sua correlação com problemas externos, pode ser encontrada em S. F. MAHMUD. A Concise History of Indo-Pakistan, p. 272-280 e 285-299.

Análise pormenorizada da mudança de regime no Afeganistão e de seu significado para a política paquistanesa, pode ser encontrado no trabalho de Abelardo ARANTES JR. O conflito no Afeganistão e a ordem internacional. Política Externa, Vol II, n.. 1, junho-julho-agosto de 2002, p. 41-65. São Paulo: USP. Adversaries fail to isolate Pakistan. The Nation. 13.04.2003, p. 5. Mehtab HAIDER. \$200 m write-off for backing terror war. The Nation. 04.04.2003, p. 1. Nadeem MALIK. Pakistan, US sign debt write-off accord, The News. 06.04.2003, p. 1. Ihtasham ul HAQUE. US Congress OKays \$1 billion debt write-off. Dawn. 04.04.2003, p. 1. Artigo de Anwar IQBAL. Pakistan needs to be watched: US scholars. Dawn. 05.04.2003, p. 18. Marchers demand Bush, Blair trial. Dawn. 05.04.2003, p. 20.

13 Shahzada ZULFIQAR. MMA asks government to give up pro-US policy. The Nation. 03.04.2003, p. 1.

14 Syed Bukhar SHAH. ANP rally urges Musharraf to announce jihad against US.

15 Syed Mohammad Tariq PIRZADA. The soldout Arab leadership. The Nation. 03.04.2003, p. 7. Ver também editorial “Arab League’s cry of despair”. Dawn. 03.04.2003, p. 7: “... [há] growing disillusionment among the members with the efficacy of the group. [O SecretárioGeral Amr] Mussa specifically refers to the Arab League's 'failure' to deal with the Palestinian problem and the Iraqi crisis [...]”.

16 Rauf ARIF. Senate strongly deplores US war against Iraq. The Nation.03.04.2003, p. 1.

17 Conforme reproduzido em The Nation, em 02.04.2003, p. 12: US to take up Indo-Pak issue after Iraq: Powell.

18 US, UK ask Pakistan to stop 'infiltration’: Straw. The Nation. 04.04.2003, p. 12. Note-se que o Paquistão nega terminantemente a tese da infiltração sistemática a partir de seu território. Not fit for pre-emption. The Nation. Editorial, 07.04.2003, p. 6. 
20 No parallel between S. Asia, Iraq. The Nation.11.04.2003, p.1. Ver também mesmos termos em The News, mesmo dia.

21 Fernandes endorses Sinha's comments. The Nation. 12.04.2003, p. 12.

22 "The president said policies of the last three years had contributed to strengthning the country's security. These policies also safeguarded vital strategic interests [...]”. Country's security insured: president..Dawn. 12.04.2003, p. 16.

23 Masud Akhtar SHEIKH. A wake-up call. The News. 04.04.2003, p. 6.

24 Shafqat MAHMOOD. Winning hearts and minds. The News. 04.04.2003, p. 7.

25 Shireen MAZARI. Murder most foul. The News. 02.04.2003, p. 6.

26 The News. 03.02.2003, p. 1.

27 Khalid AKHTAR. A visit loaded with stakes. The News. 03.02.2003, p. 1.

28 Siegfried MORTKOWITZ. What makes Chirac persist?. Dawn. 14.03.2003, p. 12.

29 Ver análise de J. N. DIXIT: “The prospect of a China-Pakistan defence and nuclear strategic nexus assumes critical dimensions for India’s defence planning [...]”. Dixit considera fundamental que se promova a aproximação entre a Índia e a China. Across Borders: Fifty Years of India's Foreign Policy. Nova Délhi: Picus Books, 1998, p. 418.

30 N. Korea handed missile technology to Pakistan: US. The Nation. 03.04.2003, p. 1, e Penalties not N-related, says US. Idem.

31 Sultan AHMED. Chinese investment package. Dawn. 03.04.2003, p.7. Agradecimentos de Musharraf a Zhu Rongji: ver MINISTÉRIO DA INFORMAÇÃO. President of Pakistan General Pervez Musharraf's Address at the Ground-Breaking Ceremony of Gwadar Deep-Sea Port. Islamabade, 2002, p. 15.

32 China important neighbour of New Delhi: Sinha. The Nation. 03.04.2003, p. 11.

33 Ahmad FARUQI. Quest for security. Dawn. Caderno Books and Authors, 13.04.03, p. 1-2, a respeito de seu livro Rethinking the National Security of Pakistan: The Price of Strategic Myopia.

34 "The closure of an epoch-making Joint Declaration was however scuttled twice, ostensibly by 'invisble hands' in the Indian camp [...]”. MINISTÉRIO DOS NEGÓCIOS ESTRANGEIROS. Pakistan Foreign Relations 2001. Islamabade, p.17.

35 India claims it has a case for pre-emptive strikes. Dawn. 05.04.2003, p. 20.

36 Pakistan warns against pre-emptive strike. The Nation. 04.04.2003, p. 1; e Pre-emptive doctrine rejected. The News. 04.04.2003, p. 1.

37 Talks offer serious, says Indian minister. The News. 23.04.2003, p.12.

38 Ibid.

39 Na definição de Farhan Bokahri, contributing editor do jornal The News, "The LFO is a package of constitutional amendments introduced by the previous military regime in August 2002, which effectively institutionalized the military’s role in the government of Pakistan and reduced the executive powers of the prime minister”. Farhan BOKHARI. Political disarray and LFO. The News. 10.04.2003. Para os defensores da LFO, trata-se de medida que estabiliza o regime civil no Paquistão. Análise das disposições da LFO que afetam a Constituição encontra-se em HUMAN RIGHTS COMMISSION OF PAKISTAN. State of Human Rights in 2002. Lahore, 2003, p. 30-40.

\section{Resumo}

Confrontadas com o risco de guerra nuclear entre o Paquistão e a Índia, as potências ocidentais têm procurado exercer algum controle sobre os acontecimentos no Sul da Ásia; instaram os dois países a encetar negociações 
bilaterais, promoveram a não-proliferação e aplicaram sanções de tempos em tempos. O Paquistão é muito sensível às políticas ocidentais, sobretudo às dos Estados Unidos, porém nunca abriu mão de dois critérios fundamentais de sua política externa: a exigência de autodeterminação para a Cachemira e a dissuasão nuclear. Os Estados Unidos agora mostram um poder e uma influência incontrastáveis, mas após a crise do Iraque a unidade das grandes potências revela fissuras. Ao mesmo tempo, o retorno ao regime civil e parlamentar no Paquistão aumenta a força dos partidos nacionalistas e islâmicos, que querem conter a influência dos Estados Unidos e ampliar os laços com a França, a Alemanha, a Rússia e a China. Nesse novo e fluido ambiente político, a evolução das relações entre o Paquistão e a Índia terá forte impacto sobre as estratégias ocidentais para o Sul da Ásia e para o mundo em geral.

\section{Abstract}

Faced with the risk of a nuclear conflict between Pakistan and India, the Western powers have tried to exert a measure of control upon events in South Asia; they urged those two countries to start bilateral negotiations, promoted nonproliferation, and from time to time applied sanctions. Pakistan is very sensitive to Western policies, above all those of the United States, but it never gave up two fundamental criteria of its foreign policy: the demand of self-determination for Kashmir and nuclear deterrence. The United States now shows unmatched power and influence, but after the Iraqi crisis the unity of the great powers became shaky. At the same time the return to a civilian and parliamentarian regime in Pakistan added strength to the nationalist and Islamic parties, which want to contain United States influence and favour increased links with France, Germany, Russia, and China. In this new, fluid political environment, the evolution of Indian-Pakistani relations will have a strong impact on Western strategies for South Asia and for the world at large.

Palavras-chave: Paquistão; Índia; Estados Unidos ; Grandes Potências; Cachemira; Guerras no Sul da Ásia; Dissuasão Nuclear; Ataque Preventivo.

Key words: Pakistan; India; United States; Great Powers; Kashmir; Wars in South Asia; Nuclear Deterrence; Pre-emptive Attack. 